\title{
REVOLUÇÃO: DA ANAKYKLOSIS À UTOPIA LIBERAL DE SIEYÈS
}

\author{
Bernardo Bianchi \\ CHSPM (Centre d'histoire des Systèmes de pensée moderne) da Paris 1, França; \\ OPLOP/UFF (Observatório dos Países de Língua Oficial Portuguesa), \\ Rio de Janeiro, RJ. Brasil. E-mail < bernardobianchi@gmail.com >
}

http://dx.doi.org/10.1590/ 0102-6445107-137/97

Revolução e emancipação não são meras categorias mobilizadas acidentalmente por Marx, são antes os nomes pelos quais, desde o final do século XVIII, se denominou, no Ocidente, as transformações políticas e sociais. Todos conhecem a anedota escolar a respeito do diálogo entre Luís XVI e o Duque de La Rochefoucauld-Liancourt, supostamente ocorrido na noite de 14 de julho de 1789, quando a Bastilha foi posta abaixo. Ao ser informado da liberação de alguns prisioneiros e da deserção das tropas realistas diante dos ataques populares, Luís XVI teria perguntado:

- É uma revolta?

- Não, Sire, é uma revolução!"

Hannah Arendt (1990, pp. 47-48) sugere que, neste diálogo, frequentemente aduzido como sendo aquele que consagrou o uso do termo revolução no seu sentido político, decantando do céu à terra o significado dessa palavra, podemos perceber a ênfase no caráter irresistível do movimento. Muito embora não possamos concordar com Arendt, que acreditava 
ter sido esta a primeira aplicação do termo com vistas à irreversibilidade, fica claro, no diálogo, o destaque àquilo que está além do poder humano, àquilo que não pode ser refreado. Esse uso, que está em conformidade com as mobilizações mais remotas do termo, distingue o conceito daquele de revolta, que se refere ao âmbito dos incidentes contornáveis. A revolução, acontecimento irrefreável, parece ser, como o movimento dos astros, regido por leis superiores àquelas dos homens. Mas o diálogo possui uma segunda dimensão e revela, no seu aspecto sumário, os novos conteúdos que o conceito começava a envolver, a saber, a abertura para o futuro.

No livro "Révolution": histoire d'un mot, Alain Rey (1989, p. 34) conta que, desde o século XII, o emprego do termo esteve ligado aos contextos dos estudos dos astros e da cronologia, em que revolução significava, preponderantemente, o retorno de um astro a um mesmo ponto da órbita celeste, o que marcava, também, o final de um tempo. Em 1543, surge a obra de Copér108 nico De revolutionibus orbium coelestium, consagrando o uso do termo revolução no âmbito da nova ciência dos astros que então nascia. Do século XV ao século XVIII, o conceito desce sobre a Terra para evocar a subordinação dos fenômenos humanos a leis superiores, precisamente como percebe Arendt. Mas uma vez aplicada às mutações ocorridas na vida humana, ainda sob o jugo da metáfora celeste, tal palavra implica a concepção do mundo humano enquanto realidade secundária, subordinado a leis universais que o transcenderiam, na qualidade de uma natureza primeira. Revolução seria, pois, concebida como uma sequência de eventos que, embora dissessem respeito aos homens, colocava-se além da sua capacidade de ação, revestindo-se, então, de um notável aspecto trágico.

No verbete "Révolution" do Dictionnaire Politique, editado por Pagnerre, Barthélemy Hauréau (1842, pp. 846-47) lembrava que a expressão de cuja redação ele se ocupara esteve associada à sucessão cíclica dos regimes de governo, tal como elaborada na tradição greco-romana. O termo havia mudado 
radicalmente de significado, tendo ultrapassado, inclusive, os matizes sugeridos pelo diálogo anedótico entre La Rochefoucauld-Liancourt e Luís XVI. Tanto é assim que Hauréau sentia necessidade de referir o leitor a outros tempos, quando a aplicação do conceito no âmbito da política estava marcada

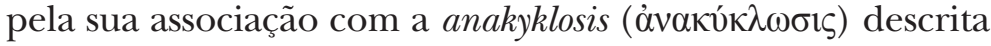
por Políbio e que pressupunha a existência de uma ordem preestabelecida segundo a qual se daria a sucessão de seis formas básicas de regime político, sendo três delas boas e as demais más, de modo que cada forma boa degenera naturalmente no seu correlato negativo, o qual, por sua vez, dá origem a uma forma boa de regime político e assim sucessivamente, num ciclo sem fim de degeneração e regeneração, desordem e mudança. Dessa associação entre revolução e anakyklosis resultava que os homens permaneciam como que irremediavelmente atrelados a transformações que, a rigor, nada traziam de novo à sua experiência política. O conceito permanecia sob a influência dos astros. De fato, no final do século XVI, Loys Leroy (1575), no seu De la vicissitude ou variété des choses en l'univers, estabelecia a relação entre o termo revolução e o ciclo de regimes de governo:

A primeira das constituições é a Monarquia, erigida naturalmente: a qual, por bom estabelecimento, engendra a realeza. Mas quando a realeza se transmuta nos seus próximos vícios, como tirania, da sua abolição resulta a Aristocracia que se modifica comumente em oligarquia. E quando os cidadãos punem a injustiça dos governantes, segue-se a democracia: pelos excessos e iniquidades da qual é erigida, resulta a oclocracia. Tal é a revolução natural das constituições, segundo a qual o Estado da República muda e se transmuta, e novamente faz o mesmo retorno (Leroy, 1575, p. 15; grifos nossos) ${ }^{1}$.

1 Todas as citações em língua estrangeira foram traduzidas de forma livre pelo autor. 
A utilização do termo revolução no campo da experiência humana estava, então, no século XVI, rigidamente associada ao decurso temporal, pelo que a palavra não revelava ainda uma dimensão normativa. Mesmo quando o conceito ultrapassa seu enquadramento regressivo, abrindo-se para a novidade de um futuro incerto porém salutar, a referência ao tempo aparece sob o manto de um fantasma jamais exorcizado: as revoluções sempre pedirão licença a Cronos, que desde os tempos da metáfora celeste é seu sinistro senhor. Feitas pelo tempo, as revoluções serão, sob as penas de Bossuet e De Maistre, como que o efeito entrópico e trágico de um reequilíbrio do sistema, verdadeiro acerto de contas com a Providência. Feitas pelos homens em memória do tempo, elas são a restauração da ordem natural das coisas, e serão reverenciadas por Burke sob sua forma ideal - a Revolução Gloriosa de 1688. Feitas pelos homens a favor dos novos tempos, elas são, sob a militância de Sieyès, a luta contra a opressão, opressão 110 esta que não é senão o sintoma de um descolamento entre o tempo da política e os novos tempos da sociedade e da razão.

Sob a sombra dos astros, a palavra revolução revela, na dança eterna entre regeneração e decadência, uma estranha associação entre tempo e transformação. Ainda que elas estejam localizadas no tempo, essa localização é indefinida, de modo que as revoluções simplesmente sucedem; elas não constituem, propriamente, o ponto culminante de uma história pregressa. Trata-se, então, de um tempo vazio, sobranceiro à duração dos eventos históricos, em que os diferentes estados sucessivos não se conectam uns com os outros e são igualmente referidos a um elemento externo, a saber, os desígnios de Deus. As revoluções são, por conseguinte, realizadas pelo tempo, mas por um tempo absolutamente indiferente às ações humanas - conscientes ou inconscientes. Este é o tempo de outrem - dos astros, da Providência, de uma história da qual os homens não são senão atores ou figurantes, um tempo sem duração. 
É preciso destacar que essa concepção do tempo não enseja, por si mesma, a aceitação fatalista dos acontecimentos tal como eles ocorrem. Nas utopias milenaristas, o quiliasta espreitava em tensa expectativa a realização imediata do milênio por vir, o que redundava em eclosões revolucionárias, sem que fosse necessário haver qualquer articulação interna ao tempo que sugerisse o advento do reino de Deus. Esvaziado o tempo, as expectativas quiliásticas reivindicam todo e qualquer momento - cada segundo seria igualmente capaz de redimir o mundo. Posteriormente, a revolução retoma sua descida sobre a Terra até o momento em que, de Burke a Sieyès, ela se torna o próprio índice da nova articulação do tempo com a história, o tempo como vir a ser. Os conceitos modernos de revolução são, portanto, históricos, na medida em que eles reivindicam uma progressiva relação com os acontecimentos histórico-sociais. As revoluções já não serão feitas pelo tempo, como se este fosse investido de uma potência celeste e a-histórica, mas, sim, no tempo - quer, na lógica reformista inerente ao conservadorismo, em honra à própria acumulação histórica, quer, sob o signo da razão iluminista, em favor dos novos tempos que irrompem do passado em direção ao futuro.

Tomamos Sieyès por considerá-lo um autor duplamente exemplar: tanto com relação à sua forma de conceber a revolução quanto no que diz respeito à relação da revolução com o tempo. Sieyès exemplifica, com efeito, o modo peculiar como o liberalismo articulou a revolução com o tempo. Com relação a este autor, nosso objetivo não se restringe, portanto, a demonstrar que seu conceito de revolução é historicamente e socialmente determinado, o que significaria dizer que também ele encerra uma cumplicidade com o passado ou, ao menos, com certo estágio do desenvolvimento socioeconômico. Trata-se, sobretudo, a partir de seus escritos políticos, de demonstrar (i) a presença da conclamação de certa chancela 
do tempo e (ii) como esse aval do tempo se articula com o primado da revolução política sobre a revolução social. Socializada sob o governo jacobino, a Revolução Francesa somente poderia ocasionar, na avaliação de Sieyès (1794, p. 49), a "ruína completa de todas as relações que ligam os homens e as coisas na ordem civil e na ordem econômica". A revolução política de Sieyès implica uma espécie de reconciliação com a ordem natural e racional - e, por isso, ela é fragmentadora da realidade vigente -, mas ela assume, simultaneamente, que essa racionalidade já se encontra presente no corpo social. A revolução visa, portanto, à transformação da ordem política, mas a ação revolucionária deverá limitar seu campo de batalha aos limites estabelecidos pelo tempo, adiando para o futuro a realização de outros conteúdos, o que implica um distanciamento com relação à questão social e uma demarcação formal do campo político.

\section{Sentidos premonitórios às vésperas da Revolução: a abertura ao novo}

No século XVIII, o vocábulo revolução continua a remeter, com maior frequência, à ideia de decadência e mesmo de catástrofe, ao ciclo de transformações irresistíveis que sacode periodicamente cada sociedade existente sobre a Terra. O verbete "Révolution", da Encyclopédie editada por Diderot e d'Alembert e cujo volume que nos concerne foi publicado pela primeira vez em 1765, registra a seguinte definição:

REVOLUÇÃO, s. f. significa, em termos políticos, uma mudança considerável que acomete o governo de um Estado.

\footnotetext{
2 Nesse sentido, nossa posição contrasta vivamente com aquela de Keith Michael Baker (1988, p. 337), que caracteriza o "momento Sieyès" em contraste com o "momento Maquiavel", de Pocock, através da "afirmação de uma vontade política que se descola completamente da história”. Sustentamos que, antes, trata-se de dois conceitos distintos de história: de um lado, trata-se de defender um conceito tradicional de história; do outro, de um conceito de história fundado numa visão extraída da economia política e do Iluminismo, com fortes afinidades com Voltaire, como veremos.
} 
Esta palavra vem do latim revolvere, rolar. Não existem Estado que não tenham sido acometidos por mais ou menos revoluções. $\mathrm{O}$ abade de Vertot nos deu duas ou três histórias excelentes das revoluções de diferentes países; a saber, as revoluções da Suécia, aquelas da república romana etc.

REVOLUÇÃO (Hist. mod. da Ingl.). Embora a Grã-Bretanha tenha experimentado a todo tempo muitas revoluções, os Ingleses consagraram este nome, particularmente, àquela de 1688, em que o príncipe d'Orange, Guilherme de Nassau, ascendeu ao trono no lugar de seu sogro, James Stuart. A má administração do rei James, diz milorde Bolingbroke, fez a revolução parecer necessária, e a tornou realizável, mas esta má administração, assim como toda sua conduta precedente, provinha de sua adesão cega ao papa e aos príncipes do despotismo, da qual nenhuma advertência pudera demovêlo. Essa adesão decorria do exílio da família real; esse exílio teve seu princípio na usurpação de Cromwell; e a usurpação de Cromwell fora ocasionada por uma rebelião precedente, iniciada não sem fundamento com relação à liberdade, mas sem nenhum pretexto válido relativo à religião (Jaucourt, 1765, p. 237; grifos nossos).

Assinado por Louis de Jaucourt, o verbete trata ainda dos empregos do termo na geometria, nos estudos dos astros e na relojoaria. A revolução se refere, então, a um acontecimento irresistível, o qual é ensejado por desvios e perturbações promovidos pela autoridade política (má administração). Diferentemente da revolta, que nada mais é do que a insurreição do povo contra o soberano, a revolução se reveste de um aspecto vindicativo, e parece, no breve relato histórico de Jaucourt, associado a uma longa série de perturbações que remontam, por fim, a um pecado originário: a usurpação de Cromwell. Esses usos permanecerão algo constante ao longo do século XVIII. 
Mesmo num autor revolucionário como Rousseau ${ }^{3}$, notavelmente pessimista a respeito do decurso do tempo, a palavra revolução aparece associada à perturbação da ordem natural. Não por acaso, a história será, por conseguinte, necessariamente repleta de revoluções, ou seja, de episódios de degeneração e ruína. É o que se nota no Discours sur l'origine et les fondements de l'inégalité parmi les hommes, publicado em $1755^{4}$. Rousseau (1964, p. 148) fala, então, das "revoluções a que o tempo necessariamente conduz", em que as mesmas assumem um aspecto trágico. Diante da idealização de um estado primitivo conforme à natureza, o tempo, por meio de suas revoluções, precipita o homem em estágios civilizatórios progressivamente piores. Também é possível perceber o uso do termo no âmbito da geologia, o que nos permite situar a expressão na vizinhança das catástrofes naturais (Rousseau, 1964, p. 167). Com efeito, em Rousseau, como em outros autores da época, os sentidos 114 da expressão se encontram como que sobrepostos, sendo difícil encontrar aplicações estritamente políticas, que não se deixem tocar pelos sentidos oriundos dos seus usos nas ciências da natureza. De modo geral, os usos políticos da palavra remetem o leitor à ideia de guerra civil. Em 1762, em Émile, o vaticínio de Rousseau é, a esse respeito, trágico:

Você acredita na ordem existente da sociedade sem pensar que esta ordem está sujeita a revoluções inevitáveis, e que é impossível prever ou prevenir aquela que pode atingir vossos filhos. O grande torna-se pequeno, o rico torna-

\footnotetext{
3 Para um estudo meticuloso dos empregos do termo révolution na obra de Rousseau, ver Rey (1989, pp. 39-52).

4 São dez as ocorrências do termo révolution no texto de Rousseau (1964, pp. 148, 167, 168, 171 [duas vezes], 187 [duas vezes], 190 [duas vezes] e 191). Há ainda mais uma ocorrência na dedicatória, intitulada À la république de Genève (Rousseau, 1964, p. 113).

5 Há uma segunda ocorrência na mesma linha: "as revoluções a que o tempo conduzirá necessariamente” (Rousseau, 1964, p. 190).
} 
se pobre, o monarca torna-se súdito; serão os golpes do destino tão raros que podereis contar de ser-lhes isento? Nos aproximamos do estado de crise e do século das revoluções (Rousseau, 1969, p. 468) ${ }^{6}$.

No mesmo período, Voltaire atribui ao vocábulo um sentido mais ambíguo do que fazia Rousseau, mas não será possível imputar-lhe um valor exclusivamente positivo. Nas suas obras históricas, Voltaire mobiliza o termo de modo predominantemente negativo. Em Le siècle de Louis XIV, publicado em 1751, ele se vale da expressão para denominar um evento político pelo qual ele não demonstra qualquer apreço: a Revolução Inglesa de 1648 (cf. Voltaire, 1819, p. 200). Referida, pois, ao campo político, a expressão aparece sob as formas: revolução do palácio e revolução do Estado. Voltaire tem, contudo, dois conceitos de revolução. Além do conceito referente à política propriamente dita, existe também a revolução no espírito humano ${ }^{7}$, a qual, referindo-se à dimensão sociocultural, revela, frequentemente, um valor positivo. No capítulo I, Voltaire usa o termo para classificar o desenvolvimento e avanço da razão na França de Luís XIV, precisamente no período conturbado compreendido entre os últimos anos de Richelieu e a morte de Luís XIV: "a sã filosofia não foi conhecida senão neste tempo" (Voltaire, 1819, p. 189).

Na sua obra Essai sur les mœurs et l'esprit des nations, de 1756, novamente, percebem-se os dois conceitos de revolução convivendo lado a lado. Voltaire emprega a palavra revolução em diversos momentos do texto para se referir a mudanças inesperadas, estranha combinação de acaso e Fatum, que tanto acometem os costumes, a cultura e a reli-

\footnotetext{
6 Neste trecho, Rousseau deixa entrever um diagnóstico mais preciso: não se trata simplesmente de uma mudança profunda qualquer, mas do fim do Antigo Regime. 7 Voltaire fala, no capítulo XXIX, em "révolution dans l'esprit humain".
} 
gião de um povo quanto um governo determinado ${ }^{8}$. As referências a revoluções do espírito humano são corriqueiras, referindo-se a diversos episódios históricos, dentre os quais o advento do islamismo e a Reforma ocupam o primeiro plano. Também são frequentes os empregos do termo revolução como sinônimo de guerra civil, sedição ou mesmo guerra de independência. Nesse sentido, ele classifica como revolução a guerra de independência levada a cabo naquela região da Europa contra Felipe II da Espanha (cf. Voltaire, 1859 , p. 140 $)^{9}$, donde resultou a formação da República dos Países Baixos, pela qual ele revela admiração. Por vezes, os dois conceitos de revolução parecem se entrecruzar. Assim, a certa altura, Voltaire afirma: "se um dia a Inglaterra vier a experimentar alguma grande revolução que a mergulhe novamente na ignorância, então, ela terá milagres todos os dias" (Voltaire, 1819, p. 138). Um acontecimento político inesperado se associa, então, a uma revolução do espírito 116 humano de caráter regressivo, capaz de ensejar um retorno cíclico às trevas de outrora, quando a superstição dominava as mentes. Do mesmo modo, ao tratar da relação da Reforma com os acontecimentos políticos que culminaram na Paz de Westfalia, os dois conceitos se articulam, e Voltaire, escreve, então, a respeito de uma "grande revolução no espírito humano e no sistema político da Europa” (Voltaire, 1859, pp. 1-7).

Voltaire (1817a) imprime ao nosso vocábulo, em 1764, na correspondência com o Marquês de Chauvelin, um valor próximo à revolução dos espíritos, o qual, conectado aos tempos em curso, revela um sentido positivo: a revolução como

\footnotetext{
8 Voltaire emprega o termo révolution 109 vezes no corpo do texto - lembrando que se trata de uma obra extensa, composta por 197 capítulos -, sendo que as ocorrências de caráter sociopolítico ultrapassam em muito as ocorrências de valor astronômico ou geológico: 97 contra 12.

9 Neste capítulo, o $164^{\circ}$, Voltaire conecta a fundação da República das Províncias Unidas a uma revolução. As referências elogiosas a Jean de Witt, Grande Pensionário, foram feitas no capítulo IX de Le siècle de Louis XIV (Voltaire, 1817b, pp. 311 e 327).
} 
abertura para o novo. De fato, enquanto nos seus textos históricos, a palavra revolução - frequentemente grafada no plural, oscilando entre o conteúdo político (revolução do Estado) e o conteúdo sociocultural (revolução dos espíritos) - parece cingida por ambiguidades, quando não revela um sentido negativo, na sua correspondência, o que se percebe é um uso positivo da expressão - desta vez, no singular. Na carta a Chauvelin, Voltaire elogia a Gazette Littéraire que, dentre todos os periódicos, é aquele que "melhor divulga as ciências da Europa" (Voltaire, 1817a, p. 752) e profetiza:

[...] tudo o que vejo lança as sementes de uma revolução que virá sem falta e da qual não terei o prazer de ser testemunha. Os franceses chegam tarde a tudo, mas, por fim, eles chegam. A luz se espalhou progressivamente de tal maneira que ela irromperá em chamas na primeira oportunidade; e, então, haverá um grande estrondo. Os jovens são realmente felizes; eles verão coisas belas (Voltaire, 1817a, p. 752).

Apesar da imagem fulgurante presente nesta carta, Voltaire imaginava, sobretudo, uma revolução tranquila (cf. Voltaire, 1817 c, p. 560 $)^{10}$, havida, antes, sobre os sentimentos e opiniões do que diretamente sobre as instituições políticas. Não se tratava, escreve Voltaire ao Conde d'Argental a 27 de fevereiro de 1769, "de fazer uma revolução nos Estados como no tempo de Lutero e de Calvino, mas de fazer uma nos espíritos daqueles que são feitos para governar" (1817b, p. 332). Voltaire demonstra predileção pela dimensão sociocultural da palavra, que sugere uma temporalidade distendida, um verdadeiro processo. A revolução de Voltaire é, pois, um acontecimento diretamente ligado ao próprio desenvolvimento espiritual da sociedade, de modo que se trata, primei-

${ }_{10}$ Trata-se da Lettre à M. Allamand, de 17 de junho de 1771 . 
ramente, de um evento intelectual e moral e, apenas secundariamente, de um fenômeno político, cujos tons parecem convergir mais para uma reforma do que propriamente para aquilo que, hoje, entendemos por revolução. A revolução permanece, portanto, referida ao tempo, o qual, por sua vez, aguilhoado pelo otimismo iluminista, é revestido de significado, o que se dá sob a ideia de progresso. Ou seja, a revolução é o próprio processo de realização de uma espécie de utopia.

\section{A palavra e a coisa: revolução e Revolução}

A partir de 1789, os conteúdos da palavra revolução são definitivamente capturados pela Revolução Francesa, sobrevindo-lhes, a todo tempo, novas cargas semânticas oriundas dos movimentos que agitam a sociedade ${ }^{11}$, de modo que os usos do termo se modificam após 1789, e novamente depois da primeira contrarrevolução, em 1791. Após a queda dos girondinos e do triunfo da Montanha, o vocábulo já fulgura reple118 to de novas significações, as quais recuarão juntamente com o Termidor, em julho de 1794. E assim, sucessivamente, em reviravoltas e recidivas, o conceito se deixará impactar pela realidade cambiante que ele insiste em procurar nomear. Desde a sua associação com o constitucionalismo, em 178912, até a progressiva radicalização, mediante a incorporação de novos conteúdos: republicana, democrática, popular, religiosa, social-e, finalmente, permanente e universal ${ }^{13}$. Com a Revo-

\footnotetext{
${ }^{11}$ Sobre isso, Reichardt e Lüsebrink (1988, p. 39) notam que "os verbetes révolution dos dicionários sociopolíticos publicados entre 1789 e 1796 cristalizam um campo semântico onde transparecem distintivamente os efeitos dicotomizantes que a experiência revolucionária exerceu imediatamente sobre a noção".

12 A esse respeito, é ilustrativo o preâmbulo do "Cahier des demandes et instructions du Tiers-État de la prévôté et vicomté de Paris hors les murs", redigido entre 11 e 28 de abril de 1789: "Uma gloriosa revolução se prepara. A mais potente nação da Europa vai se dar uma constituição política a si própria, isto é, uma existência inflexível, na qual os abusos da autoridade serão impossíveis" (Afforty et al., 1869, p. 237). O corolário é evidente: não há revolução sem Constituição.

${ }^{13}$ Seguimos aqui, como em outros momentos, as indicações precisas de Reichardt e Lüsebrink (1988).
} 
lução Francesa, os antigos empregos da expressão revolução, que, sob o Antigo Regime, permaneciam marcadas, quer por um valor regressivo, quer por uma acepção neutra e descritiva, são antagonizados pelos acontecimentos políticos, que imprimem ao conceito o valor de abertura ao futuro incerto que, então, se descortinava.

Nascido no âmbito da descrição dos movimentos celestes, o conceito de revolução permaneceu como que conectado ao ciclo das formas de governo descrito pela anakyklosis. Quando não significava simplesmente a transformação, frequentemente degenerativa de um Estado sob o manto das guerras civis, ele significava simplesmente a mudança de soberano ou de instituições políticas. Em nenhum caso, o termo denominava a transformação da organização social. Designava, sim, sob a inspiração da Revolução Americana, a luta contra o despotismo e os abusos do governo, mas o conceito não era usado para fazer o elogio de qualquer sequência de eventos em meio à qual uma população subjugada almejasse a redistribuição de poder na sociedade; não era assim empregada a expressão até que aqueles acontecimentos tomassem lugar e Robespierre se sentisse desembaraçado para afirmar: "A República? A Monarquia? Eu não conheço senão a questão social”. Revolução se precipita definitivamente sobre o mundo, inscrevendo-se no campo da atividade humana. Em setembro de 1791, após a aprovação da Primeira Constituição francesa, assomava-se a imagem da incompletude da obra revolucionária, que não poderia terminar, portanto, com o estabelecimento de um novo ordenamento jurídico. Para que a Revolução chegasse ao seu termo final, seria preciso que

[... a Constituição fosse consolidada, uma vez que a queda e o enfraquecimento da Constituição devem necessariamente prolongar a Revolução, que não é outra coisa senão os esforços da nação para conservar ou para conquistar a liberdade (Robespierre, 1952, p. 746). 
Se, em 1789, não se poderia conceber uma revolução sem uma carta constitucional, a 5 de novembro de 1792, no curso do julgamento de Luís XVI, do alto da tribuna da Convenção Nacional, Robespierre (1958, p. 89) afirmava: "Cidadãos, quereis uma revolução sem revolução?”. O paroxismo revelava a transmutação do conceito: a revolução está sempre além das instituições, as quais, quando não são vestígios de um regime de que se trata de eliminar, são simples objetivações de um processo revolucionário que, de qualquer modo, jamais poderá se resumir a elas. Se, na experiência norte-americana, a fundação da liberdade pôde se assentar na eliminação do despotismo, a Revolução Francesa teria de ir além - teria de enfrentar as próprias condições do despotismo, razão pela qual ela deveria ser, também, uma revolução social. Na mesma seção da Convenção Nacional, Robespierre (1958, p. 88), em resposta às críticas dos girondinos, que acusavam a adoção de medidas ilegais, replicou: "todas estas coisas eram ilegais, tão ilegais 120 como a Revolução, como a queda do trono e da Bastilha, tão ilegais como a própria liberdade”.

No âmbito da divulgação das doutrinas revolucionárias, surgiu, a partir de 1790, um novo gênero literário: os catecismos revolucionários, que almejavam fundar uma nova moral, erigida sobre os princípios da Revolução ${ }^{14}$, mas com base no método católico de transmissão da fé. Esses panfletos se inseriam no contexto de disputa intelectual que punha em campos opostos os vários setores da sociedade. Mas mesmo os panfletos contrarrevolucionários, como o Catéchisme des aristocrates, de 1791, não deixavam de reconhecer que os acontecimentos políticos não se limitavam à contestação das instituições políticas do Antigo Regime. Tratava-se de uma luta entre dois segmentos antagônicos da sociedade, a luta dos pobres contra os ricos, pelo que a Revolução colocava em pauta a própria organização daquela sociedade e o sistema de dominação que lhe era inerente.

\footnotetext{
${ }^{14}$ Ver, a esse respeito, Beurdeley (1893).
} 
- O que é a Revolução?

- É a insurreição daqueles que não têm nada contra aqueles que têm alguma coisa, e as rebeliões dos súditos contra o rei.

- O que causou a Revolução?

- O ciúme e a inveja de alguns particulares, a ambição e a vingança de alguns grandes, o amor pela novidade foram as suas verdadeiras causas; a injustiça e o abuso, os pretextos especiosos (apud Reichardt e Lüsebrink, 1988, p. 40).

Revolução denomina, pois, uma série de episódios perniciosos e, em se tratando de rebeliões contra o rei, ilegais. $\mathrm{O}$ Catéchisme des aristocrates ainda se insere nas veredas das tentativas de associar revolução a conjuração. Do outro lado do espectro político, o termo revolução é, decerto, apreendido diversamente, como acontecimento violento com vistas à aniquilação das injustiças próprias ao Antigo Regime e à promoção da liberdade. Mas, do mesmo modo que o seu correlato contrarrevolucionário, o Catéchisme révolutionnaire trata de um conflito social entre o povo e seus opressores. As semelhanças entre os discursos são mais interessantes dos que as diferenças.

D. O que é uma Revolução?

R. É a insurreição do Povo contra seus tiranos; é uma passagem violenta de um estado de escravidão para um estado de liberdade.

D. As Revoluções conduzem sempre à liberdade?

R. Sim, quando elas, como a Revolução Francesa, têm por princípio a Igualdade e por meio, a Virtude (apud Reichardt e Lüsebrink, 1988, p. 39).

A revolução é, portanto, também, a própria designação e a explicação dessa luta que opõe, basicamente, dois segmentos da sociedade: opressores e oprimidos, a qual será interpretada por Marx em termos de luta de classes. Em fevereiro 
de 1794, no periódico alemão Der Neue Teutscher Merkur, Wieland (1794, p. 141) divulga as impressões de Mallet du Pan, que acusava os jacobinos de "fazer da Revolução Francesa uma révolution sociale, isto é, uma inversão de todos os estados ${ }^{15}$ então instituídos". No mesmo ano, o Conde Ferrand, radicado em Londres, publicava do exílio suas Considérations sur la révolution sociale, em que lamentava os infortúnios da Revolução, a qual nada mais seria do que "o meio de que se serviu para fazer a revolução social", isto é, para "minar os fundamentos da ordem social" (Ferrand, 1794, p. iv). Muito embora o termo revolução tenha continuado a designar a luta contra o despotismo e a mudança na estrutura do governo, com o desenvolvimento dos acontecimentos na França, ela passou a significar também a oposição social materializada no antagonismo entre sans-culotte e a aristocracia.

\section{Sieyès: a revolução como reconciliação final}

122 Apesar de lhe ser inerente certo aspecto normativo, a lei, segundo o paradigma normativo da Constituição e tal como concebida por Sieyès, não cria nada. Ela apenas reconhece e consagra uma situação que, embora já existente no âmbito da sociedade, não é reconhecida pela ordem política. Nessa medida, a revolução deve implicar, sobretudo, o reconhecimento de uma situação que a antecede, ou seja, não se trata propriamente de modificar, mas antes de consagrar, por meio de uma Constituição, uma mudança já ocorrida, mudança esta que espelha o desenvolvimento da sociedade e da racionalidade. Isso não quer dizer, decerto, que a revolução seja um evento inerme. Ela envolve, sim, em Sieyès, uma ruptura tanto formal quanto material com determinado estado de coisas, mas essa ruptura se fecha, retoricamente, sobre o reconhecimento de um fundamento, do qual resultaria o processo revolucionário. Eis por que, nos próprios termos do discurso de Sieyès (1970,

\footnotetext{
${ }^{15}$ A palavra alemã Staat (estado) tem aqui o sentido de estamento.
} 
pp. 119 e 150), não se tratava de elevar aquilo que não era nada à condição de alguma coisa, mas de conceder direitos políticos àquilo que, do ponto de vista socioeconômico, já era tudo, era a própria realidade nacional.

Dá-se, então, a preexistência do sujeito revolucionário com relação à revolução, a qual não tem outro propósito senão conceder direitos políticos àquele que lhe deu causa. A concepção de revolução em Sieyès envolve, então, uma petição de princípio. Não há revolução sem opressão, e não existe opressão sem a existência de sujeitos cujo gozo dos seus direitos e liberdades naturais é impedido por forças opressivas. Trata-se, pois, menos de uma teoria da transformação do que de uma crítica da assimetria da ordem política com os fatores reais de poder presentes na sociedade ${ }^{16-17}$, os quais encarnavam, por sua vez, o próprio desenvolvimento do mundo racional. Uma vez que a racionalidade já havia se reconciliado com a vida social, chegava o momento da reconciliação final - entre governo e sociedade. Em vão, escreve Sieyès (1970, p. 196; grifos nossos), "os privilegiados fechariam os olhos para a revolução que o tempo e a força das coisas operaram [...]. Antigamente, o Terceiro Estado era servo, e a ordem nobre era tudo. Hoje, o Terceiro é tudo, e a nobreza é uma palavra”. Sieyès (1888, p. 17) condenava, do mesmo modo, "as opiniões feudais que não são mais estabelecidas sobre nada de real”. A revolução política se legitimava por meio desta outra revolução, a qual se confunde, nos seus matizes voltairianos, com a ideia de progresso.

Em nenhuma hipótese, a revolução deveria lidar com a superação da miséria da heteronomia, que afligia, na forma de dependência econômica, grande parte da população francesa. Tratava-se, antes, de reconhecer e conceder efeitos

\footnotetext{
${ }^{16}$ Remetemos o leitor a Schmitt (2007, p. 70): "existe uma política liberal do comércio, da igreja, e da educação, mas não há absolutamente nenhuma política liberal, apenas uma crítica liberal da política. A teoria sistemática do liberalismo concerne quase que unicamente à luta interna contra o poder do Estado".

${ }^{17}$ Para o tema dos fatores reais de poder, ver Lassalle (2000, pp. 10-12).
} 
políticos a uma autonomia que, traduzida na forma de poder econômico, já era gozada pelos segmentos mais afortunados do Terceiro Estado. Sieyès jamais compartilhou, portanto, da crença de que a renovação do Estado demandaria a modificação das relações sociais. Partidário de uma concepção constitucionalista, ele entendia por revolução "uma mutação política, uma mudança da Constituição ou do governo, e as vantagens sucessivas de uma boa legislação" (Sieyès, 1794, p. 48). E denunciava, em vista das reformas econômicas e sociais promovidas pelos jacobinos, a promoção de "uma subversão geral” (Sieyès, 1794, p. 49), subversão que não era senão o desfecho da radicalização do conceito de soberania popular, donde teria resultado os "maus planos de re-total, no lugar de planos de re-pública"18 (Sieyès et al., 1862, p. 292). Seu conceito de revolução dizia respeito, portanto, à modificação da ordem política; era, pois, eminentemente político, sendo seu caráter político o corolário de uma mudança de 124 fato que antecedia a revolução, a saber, a transformação das relações socioeconômicas.

As vantagens pelas quais os cidadãos se diferem estão além do caráter do cidadão. As desigualdades de propriedade e de indústria são como as desigualdades de idade, de sexo, de tamanho, de cor etc. Elas não desnaturam de forma alguma a igualdade do civismo; os direitos do civismo não podem estar ligados a diferenças. Sem dúvida, essas vantagens particulares estão sob a salvaguarda da lei; mas não cabe ao legislador criar vantagens dessa natureza. $A$

${ }^{18}$ O leitor notará que transitamos aqui por três períodos distintos, de 1789 a 1795 . Zapperi (1970, pp. 76-80) aponta as mudanças por que passou o pensamento político de Sieyès no período, desde um elogio da centralização política e administrativa, entre 1789 e 1792, até o mea-culpa que se seguiu ao trauma diante do governo jacobino. Ainda que existam diferenças concernentes ao exercício da soberania, sustentamos que há uma continuidade na medida em que Sieyès jamais defendeu que a autoridade política se imiscuísse ativamente na ordem social, a não ser para protegê-la. 
lei não concede nada, ela protege aquilo que é até o ponto em que aquilo que é começa a prejudicar o interesse comum. Apenas aí estão colocados os limites da liberdade individual (Sieyès, 1970, pp. 208-09; grifos nossos).

Há, então, uma estranha afinidade entre os conceitos de revolução e o conceito de Constituição, tal como desenvolvidos por Burke (1999). Nesse sentido, o conceito de revolução permanece cativo de uma lógica do reconhecimento e da consagração da realidade nacional que os conceitos de revolução parecem indicar. Ocorre que a realidade nacional em nome da qual Sieyès falava não se encontrava contemplada pela distribuição de poder político na sociedade como ocorria, no caso da realidade e da natureza de que falava Burke, as quais se faziam presentes através da tradição, das maneiras, dos sentimentos e das opiniões. Com relação a essa outra realidade - a de Burke -, Sieyès somente podia manifestar desprezo e esperar que a Revolução Francesa terminasse a obra que outra revolução - a revolução que o tempo e a força das coisas operaram - havia iniciado.

Com efeito, o conteúdo normativo do discurso de Sieyès se encontra referido a uma sociologia dinâmica, que apreende o desenvolvimento da realidade nacional, tanto nos seus aspectos intelectuais quanto econômicos. Nesse sentido, Keith Michael Baker afirma existirem, subjacentes ao discurso revolucionário de Sieyès, duas linguagens diferentes. De um lado, haveria a linguagem da economia política $^{19}$, segundo a qual a vontade política deve se subordinar a uma compreensão da organização econômica da sociedade. Do outro lado, existiria a linguagem da vontade, de inspiração rousseauista. Segundo nossa perspectiva, que nos mantém próximos de Zapperi, o modo específico como ${ }^{19}$ Baker (1988) chama essa linguagem de linguagem da razão. A expressão, porém,
nos parece equivocada. 
o conceito de revolução de Sieyès se articula à questão do tempo é reflexo de outra referência filosófica: o jusnaturalismo de Locke, o qual combina certa perspectiva jusnaturalista com elementos inerentes à economia política.

A questão social era, na perspectiva de Sieyès, posta de lado sob a dupla égide do atraso e da ignorância generalizados, que acometia os segmentos mais desafortunados da população, e os privava de participar dos novos tempos. Ser proprietário não significava apenas a superação de uma heteronomia material, mas indicava também a participação do indivíduo no âmbito do gênero humano. A propriedade é, então, como que o elemento externo que permite a atualização da racionalidade, da virtude e da liberdade, constitutivas da natureza humana, as quais distinguem os homens, quer dos animais, quer dos miseráveis, que encarnam uma espécie de grau zero da humanidade. As classes mais pobres são cingidas por um processo 126 de reificação que as condena a uma heteronomia absoluta:

[...] os desafortunados destinados aos trabalhos extenuantes, produtores dos prazeres de outrem, que recebem apenas o suficiente para sustentar seus corpos sofridos e carentes de tudo, neste imenso aglomerado de instrumentos bípedes, sem liberdade, sem moralidade, sem faculdades intelectuais, dotados apenas de mãos que pouco ganham e de uma mente absorvida por mil preocupações que só serve para os fazer sofrer [...], é a estes que se chamam de homens? São considerados civilizados! Mas já se viu um só capaz de entrar na sociedade? (Sieyès, 1985b, p. 81).

Nesse estado de aviltação material e moral, os miseráveis ensejam a imagem de uma multidão-criança, submetida a paixões e superstições que a mantém afastada das Luzes, impossibilitada de fazer uso de seu entendimento natural sem ser dirigida por outrem. Essa fração da sociedade, nada 
inexpressiva em critérios quantitativos, não tem voz na opinião pública, a qual é concebida como conjunto de juízos e ideias esclarecidas, produto das elites intelectuais de então.

Não devemos temer algo de ruim todas as vezes que se convoca a multidão a examinar, a julgar, a colocar a mão sobre uma máquina cuja construção interior lhe é desconhecida e da qual ela não percebeu os efeitos exteriores senão com superstição? Parece-me que vejo mãos ignorantes e muito intrépidas percorrer, pressionar, quebrar e confundir todas as engrenagens do pobre mecanismo social [...]. Dê um brinquedo às crianças, e elas o quebrarão para entendê-lo. A curiosidade ignorante quebra tudo. [...] Ora, o mecanismo social é também um brinquedo para a multidão sempre criança (Sieyès, 1985a, p. 80; grifos nossos).

Em 1789, Sieyès elabora a clássica distinção entre cidadãos passivos e cidadãos ativos ${ }^{20}$. Muito embora todos os franceses pudessem gozar dos direitos da cidadania passiva, o que incluiria um conjunto de garantias individuais, nem todos poderiam ser contados entre os cidadãos ativos, isto é, entre aqueles que poderiam influenciar ativamente na coisa pública. Todos podem, então, escreve Sieyès (1789a, p. 21),

[...] gozar das vantagens da sociedade; mas apenas aqueles que contribuem para o estabelecimento público são como que os reais acionistas da grande empresa social. Somente eles são os verdadeiros cidadãos ativos, os verdadeiros membros da associação.

\footnotetext{
${ }^{20}$ Essa distinção foi consagrada no artigo terceiro, seção I, da Lei de 22 de dezembro de 1789 , relativa à constituição das assembleias primárias e das assembleias administrativas: "as qualidades necessárias para ser cidadão ativo são: $1^{\circ}$ ) ser francês ou naturalizado francês; $2^{\circ}$ ) ser maior de vinte e cinco anos completos; $3^{\circ}$ ) ser domiciliado de fato no cantão, ao menos por um ano; $4^{\circ}$ ) pagar uma contribuição direta de valor local equivalente a três dias de trabalho; $5^{\circ}$ ) não se encontrar no estado de domesticidade, isto é, de servidos a soldo".
} 
Fica evidente a desconfiança de Sieyès com relação ao demos e à valorização da propriedade como condição para o pleno exercício dos direitos políticos. Desse modo, ele inclui, no interior do seu projeto de transformação, as relações de exploração econômica já existentes sob o Antigo Regime.

A concepção do contrato social sobre a qual se apoia a teoria política de Sieyès está, portanto, muito mais próxima da tradição lockeana do direito natural do que das formulações de Rousseau ${ }^{21}$. O direito fundamental do homem é o direito de propriedade, e este não apenas não pode sofrer coerção por parte do poder político como constitui o próprio fundamento da associação política. A argumentação apresentada por Sieyès em torno da relação entre liberdade e propriedade ${ }^{22}$ remonta ao capítulo cinco do Second treati$s e$, de Locke. Assim, do direito à propriedade que tem por objeto a própria pessoa, deduz-se, por extensão, o direito à propriedade real, relativa às ações e ao trabalho, depen128 dendo o gozo da liberdade, então, da "garantia de não ser molestado no exercício da sua propriedade pessoal e no uso da sua propriedade real" (Sieyès, 1789a, p. 12).

Formulador do moderno conceito de poder constituinte, o conceito de revolução de Sieyès oscila entre, de um lado, a defesa de uma soberania forte, de onde podemos deduzir uma centralização política, e, de outro, a recusa à ideia de participação popular. $O$ poder constituinte de Sieyès é a nação ${ }^{23}$, a qual se apresenta como um todo organizado pela unidade de interesses, donde resulta uma mesma vontade.

${ }^{21}$ A esse respeito, ver Zapperi (1970, pp. 44-81). Também Baker (1988, pp. 34042) procura enfatizar a distância entre a perspectiva de Sieyès e a teoria política rousseauista.

${ }^{22}$ Nos referimos, sobretudo, a Reconnaissance et exposition raisonnée des droits de l'homme et du citoyen (Sieyès, 1789a).

${ }^{23}$ Ver Sieyès (1970): "pois apenas a nação pode querer por si mesma e, consequentemente, criar leis para si" (p. 172); "Se nós carecemos de Constituição, é preciso fazer uma; apenas a nação tem o direito de fazê-la" (p. 177); e "a nação existe antes de tudo, ela é a origem de tudo. Sua vontade é sempre legal, é a própria lei. Antes dela e acima dela não existe senão o direito natural” (p. 180). 
A nação, que sob as novas relações econômicas se confunde com o Terceiro Estado ${ }^{24}$, é uma totalidade orgânica, instaurada sob uma ordem e uma vontade comuns, sem espaço para cisões e interesses de grupos. Trata-se, então, de

[...] um corpo de associados que vivem sob uma lei comum e são representados pela mesma legislatura etc. Será certo que a ordem nobre tenha privilégios, isenções, que ela ousa chamar de seus direitos, separados dos direitos do grande corpo dos cidadãos? Ela sai, assim, da ordem comum, da lei comum. Desse modo, seus direitos civis fazem dela um povo à parte na grande nação. É realmente imperium in imperio (Sieyès, 1970, p. 126; grifos nossos).

Ainda que o poder constituinte seja concebido como uma potência absoluta, a sua manifestação depende da representação política, o que o põe em curto-circuito com a própria soberania que dele decorre ${ }^{25}$. Assim, "o povo ou a nação não pode ter senão uma voz, aquela da legislatura nacional. [...] o povo não pode falar nem agir senão através de seus representantes" (Sieyès, 1818, p. 360). Autorizada pela nação, a Assembleia Nacional deteria, então, um poder absoluto para reconstruir a ordem política, eliminando os traços da ordem feudal e reafirmando as novas relações econômicas que já se desenvolviam sob o Antigo

\footnotetext{
${ }^{24}$ Cf. Sieyès, (1970, p. 124): "Quem ousaria então dizer que o Terceiro Estado não tem em si tudo o que é preciso para formar uma nação completa? Ele é o homem forte e robusto cujo braço está ainda acorrentado. Se fosse suprimida a ordem privilegiada, a nação não seria algo menor, mas sim algo. Assim, o que é o Terceiro Estado? Tudo, mas um tudo entravado e oprimido. O que seria sem as ordens de privilégios? Tudo, mas um tudo livre e florescente".

${ }_{25}$ É possível enxergarmos aqui uma afinidade entre a dinâmica de manifestação do poder constituinte e a diferenciação estabelecida por Hobbes entre ator e autor no Leviatã (Hobbes, 1839, pp. 147-53 [cap. XVI]), da qual deriva a diferenciação entre povo e multidão (Hobbes, 1841, p. 158 [cap. XII]), de tal modo que podemos concluir que o "o soberano é inerente ao povo, ou melhor, é o próprio povo" (Pires Aurélio, 2006, p. 4). O poder constituinte entra, então, em curto-circuito com a soberania.
} 
Regime. É preciso lembrar que o acesso à Assembleia Nacional passaria, segundo escreve Sieyès em $1789^{26}$, por um complexo sistema de mediações amparado por um critério censitário. Apenas as assembleias primárias poderiam escolher os representantes das assembleias municipais, os quais poderiam eleger - com base no território, população e contribuição de cada cidade - os membros da assembleia do departamento. Caberia, então, às assembleias dos departamentos eleger os delegados da Assembleia Nacional. Por um lado, o critério censitário se fazia presente na determinação do número de delegados a que cada cidade fazia jus junto às assembleias dos departamentos. Este número era, pois, condicionado pela contribuição paga por cada cidade. Por outro lado, mesmo o acesso dos cidadãos às assembleias primárias era condicionado por um critério censitário, critério este que deveria ser majorado quatro vezes a fim de permitir o acesso ao quadro de representantes responsável 130 pela validação das candidaturas às assembleias superiores. Criava-se, assim, como bem o notou Zapperi (1970, p. 59), "um verdadeiro regime de notabilidade", sobre o qual as classes pobres dificilmente teriam qualquer influência.

Sob o signo da unidade política, consubstanciada na unidade da vontade, Sieyès depurava a sociedade dos efeitos políticos do dissenso entre seus diferentes segmentes e fixava a separação entre Estado e sociedade. As relações sociais eram concebidas, então, como o fundamento da própria vida do Estado, o qual, concentrando em si mesmo toda a esfera política, reconhecia e garantia a autonomia da vida civil. A teoria lockeana do direito natural culminava, assim, com a separação entre Estado e sociedade, donde resultava um elogio do Estado enquanto único mediador possível entre os cidadãos. De um lado, as relações livres e

\footnotetext{
${ }^{26}$ Nos referimos a Observations sur le rapport du Comité de Constitution concernant la nouvelle organisation de la France (1789b, pp. 16-17 e 38).
} 
iguais inerentes à ordem civil, em que "um dá o seu tempo ou sua mercadoria, o outro entrega, em troca, seu dinheiro, não havendo subordinação, mas trocas contínuas". Do outro, um Estado cujos "diferentes ramos do poder existem à parte e são organizados [...] de maneira a não exigir dos cidadãos senão a contribuição para pagar os gastos públicos" (Sieyès, 1888, pp. 16-17). Em prol de sua convicção a respeito do verdadeiro fundamento do Estado, a saber, o Terceiro Estado e as relações sociais que lhe são inerentes, Sieyès defendia o reforço da ordem comum e a eliminação dos traços da antiga ordem feudal, que já não se sustentava sobre nada de efetivo. Era preciso que o governo não estivesse emaranhado com a ordem civil, da qual ele não era senão o seu produto. Era, enfim, em nome dos novos tempos burgueses que tudo deveria mudar, mas mudar nos limites da vida burguesa.

O dogma da separação entre o político e o social não é, contudo, uma descoberta da militância política do Terceiro Estado do qual Sieyès se fazia porta-voz. Era, sobretudo, um corolário da própria racionalização da política, que encontrou, na França, grande adesão entre os partidários do absolutismo. Só poderia existir, segundo Sieyès, uma única hierarquia, a saber, a hierarquia dos cidadãos perante o Estado. A lei era colocada "no centro de um globo imenso; sendo que todos os cidadãos, sem exceção, estão à mesma distância sobre a circunferência, e não ocupam, nela, senão lugares iguais" (Sieyès, 1970, p. 209). Inadvertidamente, Sieyès ocupou-se de consolidar uma das instituições do Antigo Regime - a "centralização encontrava de modo bastante natural, seu lugar na sociedade que esta revolução havia formado" (Tocqueville, 1860, p. 89). A concepção política de Sieyès revela, portanto, grandes afinidades com a caracterização da parapolítica de que fala Rancière (1995, p. 114): 
[...] a soberania só repousa em si mesma, porque fora dela existem apenas indivíduos. Qualquer outra instância no jogo político é apenas facção. A parapolítica moderna começa por inventar uma natureza específica, uma "individualidade" estritamente correlata ao absoluto de uma soberania que deve excluir a querela das frações, a querela das partes e dos partidos. Ela começa por uma primeira decomposição do povo em indivíduos, que exorciza de golpe, na guerra de todos contra todos, a guerra das classes em que consiste a política.

Não seria necessário esperar que a revolução abrisse os portões do político aos pobres para que, socializada, ela concluísse a obra do absolutismo, a centralização (Arendt, 1990, pp. 90-91). Sob o patrocínio de Sieyès, e longe dos pobres, a política absolutista encontrava meios de respirar em meio aos novos tempos.

Ao examinar o pensamento de Sieyès, procuramos determinar duas coisas: (i) qual seria o seu conceito de revolução e (ii) qual a relação deste conceito com sua filosofia política. Percebemos que o conceito de revolução de Sieyès caracteriza-se, diferentemente do uso que dele fazia Burke, por um antagonismo com relação à realidade. A revolução possui, então, um acentuado caráter normativo. Por outro lado, a revolução tem, forçosamente, uma medida, a qual é derivada da ordem socioeconômica, de modo que a revolução teria de ser, sobretudo, um acontecimento político com vistas ao restabelecimento da simetria entre um conteúdo socioeconômico e uma forma político-institucional. As transformações relativas ao conteúdo ficavam, assim, de fora da ação política, entregues ao desenvolvimento espontâneo das revoluções associadas ao decurso do próprio tempo, 
as quais ensejavam, de forma processual, as mudanças no espírito, nos costumes e na vida material, tal como falava Voltaire. A revolução política coroava, na forma de um acontecimento, essa grande revolução que lhe antecedia e que causava, por si mesma, imensa consternação entre autores conservadores. Burke (1999, p. 91), a esse respeito, lamentava o advento da "mais importante de todas as revoluções", qual seja, a "revolução nos sentimentos, maneiras e opiniões morais".

Do conceito de revolução de Sieyès, podemos derivar três teses:

Primeira tese - Revolução condicionada pelo social. A revolução que se coloca no horizonte da ação humana é a revolução política, a qual pressupõe uma revolução prévia que a legitima e determina os seus limites. Essa revolução anterior, que concerne tanto o campo social quanto o campo ideológico - e que nos remete a Voltaire -, contempla o desenvolvimento socioeconômico, bem como a disseminação progressiva das virtudes e dos conhecimentos que as Luzes inculcam sobre a opinião pública e sobre o próprio corpo social ${ }^{27}$. Dessa revolução antecedente, origina-se a ordem burguesa, a qual, elevada à condição de poder constituinte, é o fundamento último do Estado.

Segunda tese - A revolução pressupõe e consagra a distinção entre o político e o social. A filosofia política de Sieyès possui afinidades com a tradição lockeana do contrato, o que implica dizer que a associação política é fundada sobre determinadas relações sociais e econômicas. Nesse sentido, e com base na primeira tese, conclui-se que a revolução não pode dirigir sua ação a mudanças na vida material, as quais somente podem ser produzidas pelo desenvolvimento espontâneo da sociedade. Porém, enquanto produto desse conjunto de relações, o

\footnotetext{
27 "Estes benefícios [que derivam do Estado social] se multiplicarão à medida que a ordem social se beneficiar das Luzes que o tempo, a experiência e a reflexão espalharem na opinião pública" (Sieyès, 1789a, p. 16).
} 
Estado deve cuidar para eliminar todos os traços de contaminação do político com o social, donde resultariam distorções.

Terceira tese - Revolução enquanto luta contra a opressão. A revolução política é produto da vontade racional, e se dá sob a forma da luta contra a opressão ${ }^{28}$, a qual é concebida como a agressão oriunda de um corpo estranho à ordem comum da sociedade, a nação; a analogia com a luta entre Estados é, pois, natural: “os privilegiados não se mostram menos inimigos da ordem comum do que os ingleses dos franceses em tempo de guerra"29. O sujeito revolucionário antecede a luta contra a opressão. O sujeito revolucionário, produto da revolução ideológico-social, antecede a luta política.

Com Sieyès, podemos perceber o processo pelo qual a revolução deixa de ser o índice da anakyklosis para se tornar a própria dinâmica que abole a ciranda das transformações políticas. A revolução não é mais concebida como desagregação, como efeito trágico de sucessivos desajustamentos, 134 mas como a própria reorganização da vida social e política, a qual seria, graças à revolução, refundada de acordo com a essência da comunidade. A revolução consagra, então, a lógica de realização da política como atualização da essência própria da política. A transformação de que se trata não implica simplesmente uma modificação da forma da política, mas o próprio advento desta forma, o qual a revolução vem como que realizar. A revolução de Sieyès implica tanto a decomposição do povo em indivíduos como a instauração de uma vontade una.

\footnotetext{
${ }^{28} \mathrm{Na}$ verdade, o grande inimigo de Sieyès seria a aristocracia, ou melhor, a corte, e não propriamente o monarca. Sobre isso, ver Sieyès (1970, p. 132).

${ }^{29}$ A luta entre o Terceiro Estado contra os demais estamentos nada tem a ver, na perspectiva de Sieyès, com a luta de classes, tal como teorizada por Marx. O Terceiro Estado é toda a vida econômica da França, sendo a nobreza considerada um corpo parasitário que não participa da criação da riqueza nacional. Não há, portanto, relação econômica entre os estados, eles são corpos estranhos uns aos outros. A nobreza é um imperium in imperio (cf. Sieyès, 1970, p. 126).
} 


\section{Bernardo Bianchi}

é doutor em Ciência Política pelo Instituto de Estudos Sociais e Políticos da Universidade do Estado do Rio de Janeiro (IESP-UERJ) e em Filosofia pela Université Paris 1 Panthéon-Sorbonne; pesquisador do Centre d'Histoire des Systèmes de Pensée Moderne (CHSPM-Paris 1).

\section{Bibliografia}

AFFORTY, P. et al. 1869. "Cahier des demandes et instructions du TiersEtat de la prévôté et vicomté de Paris hors les murs". In: MADIVAL, J.; LAURENT, E. (orgs.). Archives parlementaires de 1787 à 1860. t. 5. Paris: Librairie Administrative de Paul Dupont.

ARENDT, H. 1990. On revolution. London: Penguin.

BAKER, K. M. 1988. "Sieyès" [verbete]. In: FURET, F.; OZOUF, M. (orgs.). Dictionnaire critique de la Révolution Française. Paris: Flammarion. BEURDELEY, 1893. Les catéchismes révolutionnaires. Paris: Bibliothèque Gilon.

BOSSUET, J. B. 1875. Discours sur l'histoire universelle. Paris:

Bernardin-Béchet.

BURKE, E. 1999. "Reflection on the Revolution in France". In:

Selected works of Edmund Burke. v. 2. Indianapolis: Liberty Fund.

FERRAND, A.-F.-C. 1794. Considérations sur la révolution sociale. London: [s.ed.].

HAURÉAU, B. 1842. "Révolution” [verbete]. In: PAGNERRE, L.-A. (ed.).

Dictionnaire politique. Paris: Pagnerre.

HOBBES, T. 1839. "Leviathan". In: MOLESWORTH, W. (ed.). The

English works of Thomas Hobbes. t. 3. London: John Bohn.

. 1841. "Philosophical rudiments concerning government and

society [The citizen]". In: MOLESWORTH, W. (ed.). The English

works of Thomas Hobbes. t. 2. London: John Bohn.

JAUCOURT, L. 1765. “Révolution” [verbete]. In: DIDEROT, D.;

D'ALEMBERT, J. Encyclopédie ou Dictionnaire raisonné des sciences, des arts et des métiers. t. 14. Paris.

LASSALLE, F. 2000. A essência da Constituição. Rio de Janeiro: Lúmen Juris.

LEROY, L. 1575. De la vicissitude ou varieté des choses en l'univers. Paris:

Chez Pierre l'Huilier.

MANNHEIM, K. 1954. Ideology and utopia. London: Routledge \& Kegan Paul. PIRES AURÉLIO, D. 2006. A 'multidão' e o Estado democrático. Paper apresentado no Congresso Internacional sobre a Filosofia Política de Espinosa. Lugo, Espanha. 
RANCIÈRE, J. 1995. La mésentente. Paris: Éditions Galilée.

RAYNAL, G.-T. 1780. Histoire philosophique des établissements et du commerce des Européens dans les Deux Indes. t. 2. Genève: JeanLeonard Pellet.

REICHARDT, R.; LÜSEBRINK, H.-J. 1988. "Révolution à la fin du $18^{\mathrm{e}}$ siècle". Mots, Paris, n. 16, pp. 35-68.

REY, A. 1989. "Révolution": histoire d'un mot. Paris: Gallimard.

ROBESPIERRE, M. 1952. "Séance du 29 septembre 1791". In: BOULOISEAU,

M. et al. Euvres de Maximilien Robespierre. t. 7. Paris: PUF. . 1958. "Séance du 5 novembre 1792". In: BOULOISEAU, M. et al.

Euvres de Maximilien Robespierre. t. 9. Paris: PUF.

ROUSSEAU, J.-J. 1964. "Discours sur l'origine et les fondements de l'inégalité parmi les hommes”. In: GAGNEBIN, B.; RAYMOND, M.

(orgs.). CEuvres complètes. t. 3. Paris: Gallimard. 1969. "Émile, ou de l'éducation”. In: GAGNEBIN, B. (org.).

Euvres complètes. t. 4. Paris: Gallimard.

SCHMITT, C. 2007. The concept of the political. Chicago: University of Chicago Press.

SIEYÈS, E.-J. 1789a. Reconnaissance et exposition raisonnée des droits de l'homme et du citoyen. Paris: Chez Baudouin. .1789b. Observations sur le rapport du Comité de Constitution concernant la nouvelle organisation de la France. Versailles: Chez Baudouin. . 1794. Notice sur la vie de Sieyès. Paris: Maradan. 1818. "Dire de M. l'Abbé Syeyes". In: Choix de rapports, opinions et discours prononcé à la Tribune Nationale depouis 1789 jusqu'à ce jour. Paris: Imprimerie de Cosson.

. 1888. "Essai sur les privilèges". In: CHAMPION, E. (org.). Qu'est-ce que le Tiers Etat? Précédé de l'essai sur les privilèges. Paris: Société de l'Histoire de la Révolution Française.

. 1970. “Qu'est-ce que le Tiers Etat?”. In: ZAPPERI, R. (org.).

Qu'est-ce que le Tiers Etat?. Genève: Librairie Droz.

. 1985a. "Fragment: Quand on parle mécanisme, il ne faut s'adresser qu'aux mécaniciens”. In: ZAPPERI, R. (org.). Écrits politiques. Paris: Editions des Archives Contemporaines. . 1985b. "Fragment: Grèce, citoyen-homme". In: ZAPPERI, R. (org.). Écrits politiques. Paris: Editions des Archives Contemporaines. SIEYÈS, E.-J. et al. 1862. "Séance de la Convention Nationale: le 2 Thermidor, l'an III". In: Réimpression de l'ancien moniteur.

t. 25. Paris: Typographie de Henri Plon. 
TOCQUEVILLE, A. de. 1860. L'Ancien Régime et la Révolution. Paris : Michel Lévy Frères, Libraires-Éditeurs.

VOLTAIRE, F. M. A. 1817a. "Lettre à M. le Marquis de Chauvelin (2 avril 1764)". In: CEuvres complètes de Voltaire. t. 10. Parte 2. Paris: Chez Th. Desoer. 1817b. "Lettre à M. le Comte D'Argental (27 février 1769)". In: Cuvres complètes de Voltaire. t. 11. Paris: Chez Th. Desoer. . 1817c. "Lettre à M. Allamand (17 juin 1771)". In: Euvres complètes de Voltaire t. 11. Paris: Chez Th. Desoer. . 1819. "Essai sur les mœurs et l'esprit des nations". t. 1. In: Euvres complètes de Voltaire. t. 17. Paris: L'imprimerie de Crapelet. . 1859. "Essai sur les mœurs et l'esprit des nations". t. 4. In: CEuvres complètes de Voltaire. t. 8. Paris: Librairie de L. Hachette et $\mathrm{C}^{\mathrm{le}}$.

WIELAND, C. M. 1794. "Beschluß der Addresse eines Ungenannten an die Freunde der Wahrheit". In: Der Neue Teutsche Merkur. v. 1. [Weimar: s.ed.].

ZAPPERI, R. 1970. "Introduction: la politique de Sieyès". In: ZAPPERI, R. (org.). Qu'est-ce que le Tiers Etat?. Edition Critique. Genève: Librairie Droz. 


\section{REVOLUÇÃO: DA ANAKYKLOSIS À UTOPIA LIBERAL DE SIEYÈS BERNARDO BIANCHI}

Resumo: Procuramos analisar, neste artigo, de que modo o termo revolução abandona seu conteúdo descritivo, ligado quer à metáfora astronômica quer à anakyklosis grega, para se tornar um conceito com forte caráter normativo ao longo do século XVII e, notadamente, durante a Revolução Francesa. Tomando Sieyès como pensador exemplar de uma concepção liberal, nossa intenção consiste em demonstrar de que modo esse autor articula o conceito de revolução à questão do tempo histórico. Ainda que esse conceito tenha assumido uma conotação fortemente normativa, veremos que ele continua a demandar um aval do tempo. E é justamente por meio dessa articulação específica com o tempo que Sieyès estabelece limites ao processo revolucionário, os quais tomam forma através do primado da revolução política sobre a revolução social.

Palavras-chave: Revolução; História; Revolução Francesa; Liberalismo; Conservadorismo.

\section{REVOLUTION: FROM ANAKYKLOSIS TO THE LIBERAL UTOPIA OF SIEYÈS}

Abstract: In this article, an analysis is conducted of the concept "revolution" and to what extent it ceased to have a descriptive meaning that was either derived from an astronomical metaphor or from the Greek political doctrine of anakyklosis. Instead, it became a concept with a powerful normative character throughout the 18th Century, particularly during the French Revolution. Taking Sieyes as an example of a liberal thinker, our aim is to show how far this author links the concept of revolution to the question of historical time. Although the concept of revolution has been endowed with a powerful normative connotation, it can be seen that through Sieyes, the concept still had to be upheld by the notion of time. And it is 
through this conscious link with "time" that Sieyes defines the limits of the revolutionary process which initially took shape through a social revolution being driven by a political revolution.

Keywords: Revolution; History; French Revolution; Liberalism; Conservatism.

Recebido: 28/06/2015 Aprovado: 04/12/2015 